Article

\title{
Glucose-Treated Manganese Hexacyanoferrate for Sodium-Ion Secondary Battery
}

\author{
Yutaka Moritomo $^{1,2,3, *}$, Kensuke Goto ${ }^{1, \dagger}$ and Takayuki Shibata ${ }^{1,2, \dagger}$ \\ ${ }^{1}$ Graduate School of Pure and Applied Science, University of Tsukuba, Tsukuba 305-8577, Japan; \\ E-Mails: s1320247@u.tsukuba.ac.jp (K.G.); shibata.takayuki.ka@u.tsukuba.ac.jp (T.S.) \\ ${ }^{2}$ Faculty of Pure and Applied Science, University of Tsukuba, Tsukuba 305-8577, Japan \\ ${ }^{3}$ Center for Integrated Research in Fundamental Science and Engineering (CiRfSE), \\ University of Tsukuba, Tsukuba 305-8577, Japan \\ $\dagger$ These authors contributed equally to this work. \\ * Author to whom correspondence should be addressed; E-Mail: moritomo.yutaka.gf@u.tsukuba.ac.jp; \\ Tel.: +81-29-853-4337.
}

Academic Editor: Sheng S. Zhang

Received: 8 July 2015 / Accepted: 25 August 2015 / Published: 1 September 2015

\begin{abstract}
Manganese hexacyanoferrate (Mn-PBA) is a promising cathode material for sodium-ion secondary battery (SIB) with high average voltage $(=3.4 \mathrm{~V})$ against Na. Here, we find that the thermal decomposition of glucose modifies the surface state of Mn-PBA, without affecting the bulk crystal structure. The glucose treatment significantly improves the rate properties of Mn-PBA in SIB. The critical discharge rate increases from $1 \mathrm{C}$ (as-grown) to $15 \mathrm{C}$ (glucose-treated). Our observation suggests that thermal treatment is quite effective for insulating coordination polymers.
\end{abstract}

Keywords: sodium-ion secondary battery; prussian blue analogues; glucose treatment; surface modification

\section{Introduction}

Coordination polymers are promising cathode materials for lithium-ion secondary batteries (LIBs), due to their robust nature of the frameworks against $\mathrm{Li}^{+}$intercalation/deintercalation. Among the coordination polymers, transition metal hexacyanoferrates or the Prussian blue analogues 
(PBA) [1], $A_{x} M\left[\mathrm{Fe}(\mathrm{CN})_{6}\right]_{y}$ ( $A$ and $M$ are the alkali and transition metals, respectively), are most intensively investigated as cathode materials for LIBs. The compounds show three-dimensional (3D) jungle-gym-type framework with periodic cubic nanopores, $0.5 \mathrm{~nm}$ at the edge. Imanishi et al. [2,3] reported $\mathrm{Li}^{+}$intercalation behaviors in $\mathrm{Fe}\left[M(\mathrm{CN})_{6}\right]_{y}(M=\mathrm{V}, \mathrm{Mn}, \mathrm{Fe}, \mathrm{Ni}$, $\mathrm{Cu}$ ), even though their cyclability is far from satisfactory. The cyclability is fairly improved in $\mathrm{K}_{0.10} \mathrm{Mn}^{\mathrm{II}}\left[\mathrm{Fe}^{\mathrm{III}}(\mathrm{CN})_{6}\right]_{0.70} 4.2 \mathrm{H}_{2} \mathrm{O}$ and $\mathrm{Rb}_{0.61} \mathrm{Mn}^{\mathrm{II}}\left[\mathrm{Fe}^{\mathrm{III}}(\mathrm{CN})_{6}\right]_{0.87} 2.2 \mathrm{H}_{2} \mathrm{O}$ [4]. On the other hand, thin films of $\mathrm{Li}_{1.32} \mathrm{Mn}^{\mathrm{II}}\left[\mathrm{Fe}^{\mathrm{II}}(\mathrm{CN})_{6}\right]_{0.83} 3.5 \mathrm{H}_{2} \mathrm{O}[5,6]$, shows a large capacity of $128 \mathrm{mAh} / \mathrm{g}$ and an average operating voltage of $3.6 \mathrm{~V}$ against $\mathrm{Li}$.

PBAs are also promising cathode materials for sodium-ion secondary batteries (SIBs) [7-14]. Goodenough's group [7] have reported $\mathrm{Na}^{+}$intercalation behaviors in a $\mathrm{K}-M-\mathrm{Fe}(\mathrm{CN})_{6}$ system $(M=\mathrm{Mn}, \mathrm{Fe}, \mathrm{Co}, \mathrm{No}, \mathrm{Cu}, \mathrm{Zn})$, even though their coulomb efficiency is very low. The coulomb efficiency is significantly improved in thin films of $\mathrm{Na}_{1.32} \mathrm{Mn}^{\mathrm{II}}\left[\mathrm{Fe}^{\mathrm{II}}(\mathrm{CN})_{6}\right]_{0.83} 3.5 \mathrm{H}_{2} \mathrm{O}$ [8], and $\mathrm{Na}_{1.6} \mathrm{Co}^{\mathrm{II}}\left[\mathrm{Fe}^{\mathrm{II}}(\mathrm{CN})_{6}\right]_{0.9} 2.9 \mathrm{H}_{2} \mathrm{O}$ [9]. By a structural optimization, Yang et al. [10] demonstrated that $\mathrm{Na}_{1.76} \mathrm{Ni}_{0.12} \mathrm{Mn}_{0.88}\left[\mathrm{Fe}(\mathrm{CN})_{6}\right]_{0.98}$ exhibits an excellent cycle life with a capacity of $118 \mathrm{mAh} / \mathrm{g}$. In addition, Lee et al. [11] reported that $\mathrm{Na}_{2} \mathrm{Mn}^{\mathrm{II}}\left[\mathrm{Mn}^{\mathrm{II}}(\mathrm{CN})_{6}\right]$ shows an excellent capacity of $209 \mathrm{mAh} / \mathrm{g}$ mediated by one- and two-electron reactions per a chemical formula. Wang et al. [12] reported that Rhombohedral Prussian white, $\mathrm{Na}_{1.92} \mathrm{Fe}\left[\mathrm{Fe}(\mathrm{CN})_{6}\right]$, works as a cathode material for SIBs.

Unfortunately, the coordination polymer has serious drawback, i.e., low electric conductivity. The low electric conductivity limits the rate performance of the batteries. In insulating $\mathrm{LiFePO}_{4}$ [15-19], the electric conductivity, and hence the rate property, are significantly improved by carbon-coating procedures. Here, we found that the thermal decomposition of glucose modifies the surface state of Mn-PBA, without affecting the bulk crystal structure. The glucose treatment significantly improves the rate property of manganese hexacyanoferrate (Mn-PBA) in SIB.

\section{Experimental Section}

\subsection{Sample Preparation and Characterization}

We prepared "as-grown" and "glucose-treated" Mn-PBAs. The as-grown Mn-PBA was synthesized from an aqueous solution containing $40 \mathrm{mM} \mathrm{K}{ }_{4}\left[\mathrm{Fe}^{\mathrm{II}}(\mathrm{CN})_{6}\right], 40 \mathrm{mM} \mathrm{Mn}^{\mathrm{II}} \mathrm{Cl}_{2}$, and $4 \mathrm{M} \mathrm{NaCl}$. Chemical composition of the as-grown Mn-PBA is $\mathrm{Na}_{1.72} \mathrm{Mn}^{\mathrm{II}}\left[\mathrm{Fe}^{\mathrm{II}}(\mathrm{CN})_{6}\right]_{0.93} 2.60 \mathrm{H}_{2} \mathrm{O}$, which was determined using an ICP method and a CHN organic elementary analyzer. Calcd: Na, 11.64; Mn, 16.27; Fe, 15.35; C, 19.80; H, 1.55; N, 23.09\%. Found: Na, 11.96; Mn, 16.54; Fe, 15.51; C, 19.66; H, 1.52; N, 22.74\%. The glucose-treated Mn-PBA was prepared as follows. First, the as-grown Mn-PBA was added $10 \mathrm{wt} \%$ glucose and appropriate water. The mixture was well-ground and dried at $60{ }^{\circ} \mathrm{C}$. Finally, the dried mixture was heated at $350{ }^{\circ} \mathrm{C}$ for $4 \mathrm{~h}$ in a vacuum. Chemical composition of the glucose-treated Mn-PBA is $\mathrm{Na}_{1.88} \mathrm{Mn}^{\mathrm{II}}\left[\mathrm{Fe}^{\mathrm{II}}(\mathrm{CN})_{6}\right]_{0.97} 0.99 \mathrm{H}_{2} \mathrm{O}$ with 0.78 wt \% carbon: Calcd: $\mathrm{Na}, 13.39$; Mn, 16.88; Fe, 16.72; C, 22.35; H, 0.62; N,25.15\%. Found: Na, 14.37; Mn, 17.68; Fe, 16.30; C, 22.42; H, 1.24; $\mathrm{N}, 24.56 \%$. Note that the glucose treatment reduces the water content by $1.61 \mathrm{H}_{2} \mathrm{O}$ per chemical formula. 


\subsection{Structural Characterization}

The scanning electron microscopy (SEM) images were obtained with SU8020 at Faculty of Pure and Applied Science and the OPEN FACILITY, Research Facility Center for Science and Technology, University of Tsukuba. The powder samples were attached with a silver paste on the sample holder. Then, the sample holder was dried in vacuum for several hours. The transmission electron microscopy (TEM) investigation was supported by NIMS microstructural characterization platform (NMCP) as a program of "Nanotechnology Platform" of the Ministry of Education, Culture, Sports, Science and Technology (MEXT), Japan. The sample powders were well dispersed on the micro grid. TEM and scanning TEM (STEM) images were obtained with JEM-2100F (JEOL Ltd., Tokyo, Japan) and JEM-ARM200F (JEOL Ltd., Tokyo, Japan), respectively. The acceleration voltages were $200 \mathrm{kV}$.

The X-ray diffraction (XRD) patterns were obtained using an X-ray powder diffractometer (MultiFlex, Rigaku) with the Bragg-Brentano geometry. The X-ray source was the $\mathrm{Cu} \mathrm{K}$ line at $40 \mathrm{kV}$ and $40 \mathrm{~mA}$. A Si monochromator was used to reduce the scattering by the white X-ray.

\subsection{Electrochemical Properties}

The paste-type cathode electrodes were prepared as follows. First, Mn-PBA, acetylene black, and polyvinylidene difluoride (PVDF) were well mixed with adding $\mathrm{N}, \mathrm{N}$-dimethylformamide (DMF) in a rate of 7:2:1. The mixture was pasted on an Al foil, and well dried in vacuum. The thickness of the electrodes were $58 \mu \mathrm{m}$ including Al collective electrode $(19 \mu \mathrm{m})$. The current-perpendicular-plane (CPP) resistivity of the electrodes were $39 \Omega \mathrm{cm}^{2}$ and $22 \Omega \mathrm{cm}^{2}$ for the as-grown and glucose-treated Mn-PBAs, respectively.

The electrochemical properties of the Mn-PBAs were investigated in a beaker-type cell against Na. The electrolyte was $1 \mathrm{M} \mathrm{NaClO}_{4}$ in propylene carbonate (PC). The active area of the films was $1.0 \mathrm{~cm}^{2}$. The lower and upper cut-off voltages were 2.0 and $4.2 \mathrm{~V}$, respectively. In the measurement of the rate and cycle properties, the charge rate was fixed at $0.3 \mathrm{C}$.

\section{Results and Discussion}

\subsection{Crystal Structure}

Figure 1 shows the SEM images of the as-grown and glucose-treated Mn-PBAs. The grain size $\approx 200 \mathrm{~nm}$ for both the as-grown and glucose-treated Mn-PBAs. The glucose treatment has negligible effect on the shape and size distribution. 

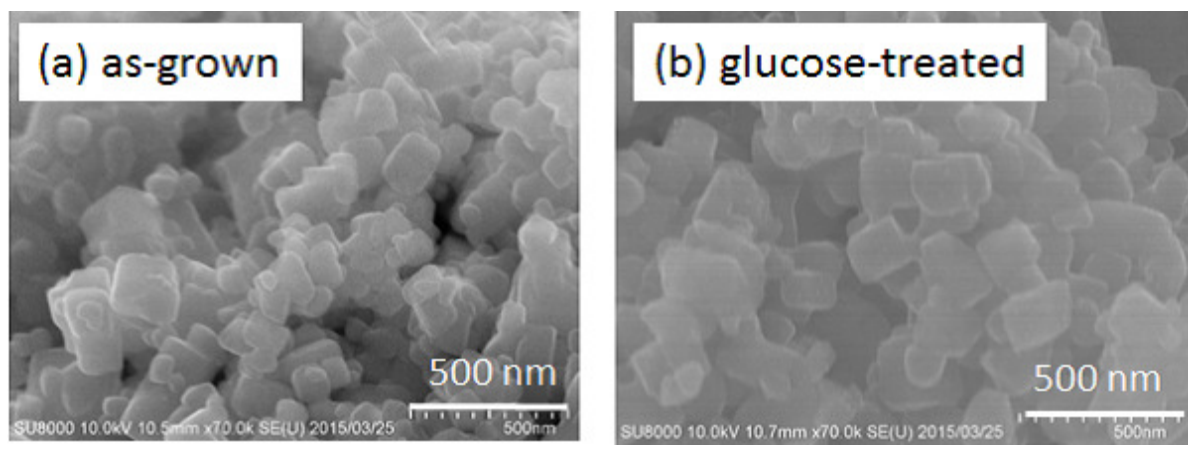

Figure 1. SEM images of (a) as-grown and (b) glucose-treated Manganese hexacyanoferrates (Mn-PBAs).

Figure 2a shows XRD patterns of the as-grown and glucose-treated Mn-PBAs. For the readers convenience, we show the XRD pattern of a prototypical PBA, $\mathrm{Na}_{1.32} \mathrm{Mn}\left[\mathrm{Fe}(\mathrm{CN})_{6}\right]_{0.81} 3.6 \mathrm{H}_{2} \mathrm{O}$, in Figure 2b. All the reflections can be indexed in the face-centered cubic setting. A careful comparison of the XRD pattern of the as-grown Mn-PBA (Figure 2a) with that of the cubic PBA (Figure 2b) reveals that the reflections at the $(220)_{C},(420)_{C}$, and $(440)_{C}$, show characteristic spitting while the reflections at $(200)_{\mathrm{C}}$ and $(400)_{\mathrm{C}}$ remain single peak. Such a feature can be ascribed to the trigonal distortion [20,21]. Actually, all the reflections can be indexed in the hexagonal setting. The XRD pattern of the glucose-treated Mn-PBA shows broadening. Nevertheless, peak splitting is discernible in the $49^{\circ}$ reflections. Note that the rather broader feature of the $24^{\circ}$ and $38^{\circ}$ reflections should be ascribed to the peak splitting. These observation indicate that the glucose-treated Mn-PBA show the trigonal distortion.

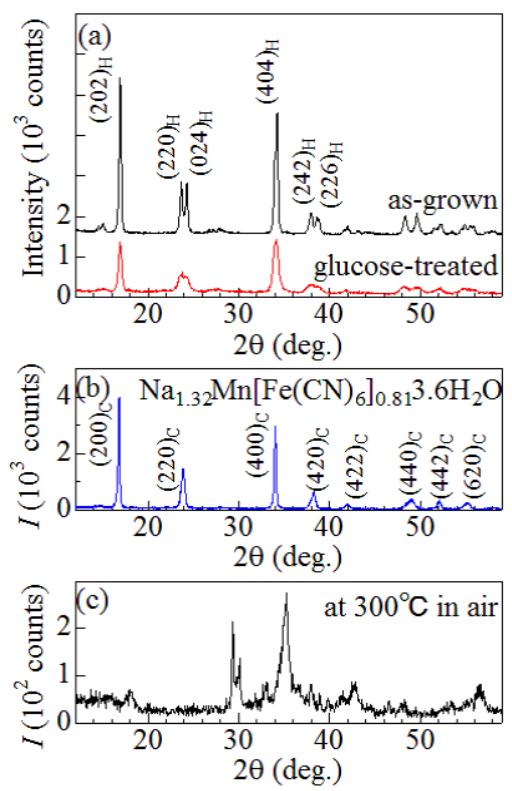

Figure 2. (a) XRD patterns of as-grown and glucose-treated Mn-PBAs. The subscripts, $\mathrm{H}$, of the index represent the hexagonal setting; (b) XRD patterns of a prototypical PBA, $\mathrm{Na}_{1.32} \mathrm{Mn}\left[\mathrm{Fe}(\mathrm{CN})_{6}\right]_{0.81} 3.6 \mathrm{H}_{2} \mathrm{O}$. The subscripts, $\mathrm{C}$, of the index represent the face-centered cubic setting; (c) XRD pattern of Mn-PBA after the heating in air at $300{ }^{\circ} \mathrm{C}$ for $90 \mathrm{~min}$. 
The cell parameters are refined by the Rietveld analysis (Rietan-PF program [22]) with the trigonal model ( $R \underline{3} m ; Z=12$ in the hexagonal setting). The obtained lattice constants are nearly unchanged: $a_{\mathrm{H}}=1.5026(7) \mathrm{nm} / c_{\mathrm{H}}=1.776(1) \mathrm{nm}$ and 1.4964(11) nm/1.764(1) $\mathrm{nm}$ for the as-grown and glucose-treated Mn-PBAs, respectively. The trigonal distortion was ascribed to the displacement of $\mathrm{Na}^{+}$ from the central position of the cubic nanopore [21]. Thus, the jungle-gym-type framework of Mn-PBA is robust against the thermal treatment in a vacuum.

The Mn-PBA will decompose on heating in air atmosphere. Figure $2 b$ shows the X-ray powder diffraction pattern of Mn-PBAs after the heating in air at $300{ }^{\circ} \mathrm{C}$ for $90 \mathrm{~min}$. The reflections due to PBA framework disappear, and extra reflections appear at $30^{\circ}$ and $35^{\circ}$. The diffraction pattern is similar to that of $\mathrm{Fe}\left[\mathrm{Fe}(\mathrm{CN})_{6}\right]_{3 / 4}$ after the heat treatment in air [2].

\subsection{Surface State}

Figure 3 show the TEM images of (a) as-grown and (b) glucose-treated Mn-PBAs. The glucose-treated particle shows humps of 10-20 nm in diameter. The humps are absent in the as-grown particles. Figure 4 show the (a) bright field (BF)-STEM image of glucose-treated Mn-PBA together with the (b) electron energy loss spectroscopy (EELS) images at the C-K, O-K, and Mn-L edges. The EELS images indicate that the hump consists of a manganese oxide core and a surrounding thin carbon layer. Such a nanoparticle is probably formed by thermal decomposition of the glucose. The oxide-based nanoparticles at the surface are responsible for the good electric contact between the conductive acetylene black and insulating PBA.

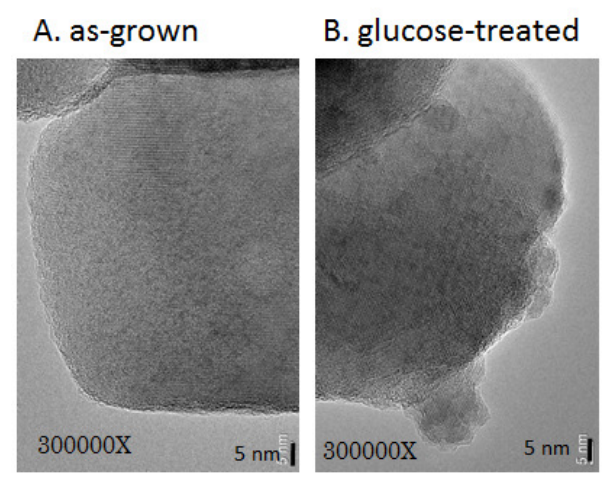

Figure 3. Transmission electron microscopy (TEM) images of (a) as-grown and (b) glucose-treated Mn-PBAs. 


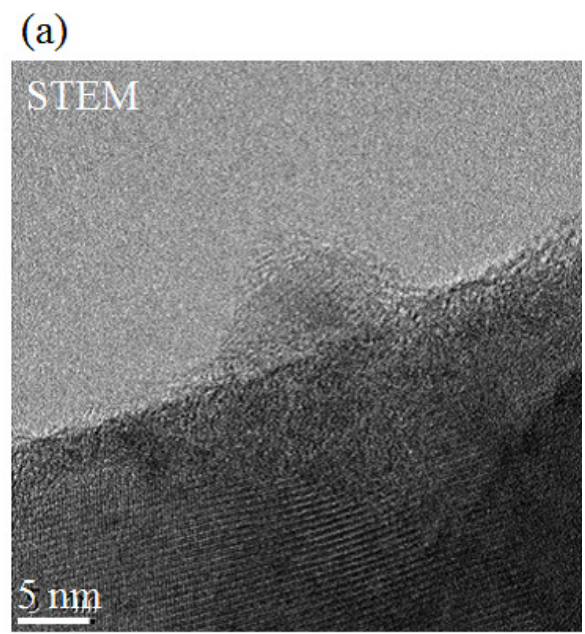

(b)

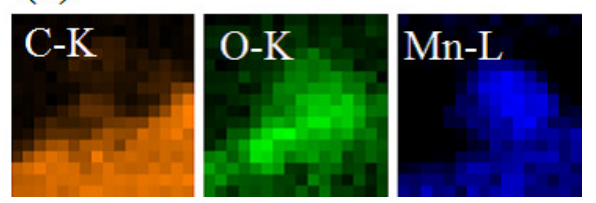

Figure 4. (a) Bright field-scanning TEM (BF-STEM) image of glucose-treated Mn-PBA; (b) Electron energy loss spectroscopy (EELS) images at C-K, O-K, and Mn L-edges.

\subsection{Electrochemical Properties}

Figure 5a shows the discharge curve at $0.1 \mathrm{C}$ of as-grown and glucose-treated Mn-PBAs. The curves are regarded as open-current-voltage (OCV) curve. To investigate the plateau structure, we plotted voltage-derivative of capacity $(-\mathrm{d} q / \mathrm{d} V ; q$ and $V$ are capacity and voltage, respectively) as red circles. In the as-grown Mn-PBA, the discharge curve shows two plateaus at 3.35 and $3.36 \mathrm{~V}$. The former and the latter plateaus are ascribed to the reduction processes of $\left[\mathrm{Fe}(\mathrm{CN})_{6}\right]^{4-}$ and $\mathrm{Mn}^{2+}$, respectively [8]. The corresponding plateau structures are observed at almost the same voltages in the glucose-treated Mn-PBAs.

Figure $5 \mathrm{~b}$ shows discharge curves of the as-grown and glucose-treated Mn-PBAs at various discharge rates. The charge rate was fixed at $0.3 \mathrm{C}$. In the as-grown Mn-PBA, the discharge capacity $(Q)$ rapidly decreases with rate from $\mathrm{Q}=88 \mathrm{mAh} / \mathrm{g}$ at $0.1 \mathrm{C}$ to $69 \mathrm{~mA} / \mathrm{g}$ at $1.0 \mathrm{C}$. The rate properties are significantly improved in the glucose-treated Mn-PBAs: the discharge capacity is discernible even at $15 \mathrm{C}$. (The absolute value of $Q$ has error of $10 \%$ probably due to the imperfect electric constant between the collector electrode and the respective particles. Actually, the $Q$ value of the glucose-treated Mn-PBA exceeds $100 \mathrm{mAh} / \mathrm{g}$ in the investigation of the cycle properties.) The improved rate property is ascribed to the oxide-based nanoparticles at the surface, which cause the good electric contact between the conductive acetylene black and insulating PBA. Actually, the glucose treatment reduces the CPP resistivity of the electrodes from $39 \Omega \mathrm{cm}^{2}$ (as-grown) to $22 \Omega \mathrm{cm}^{2}$ (glucose-treated). 
(a)

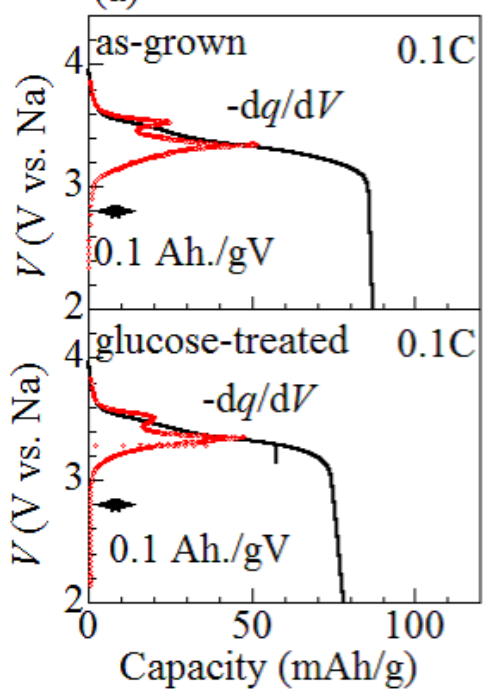

(b)

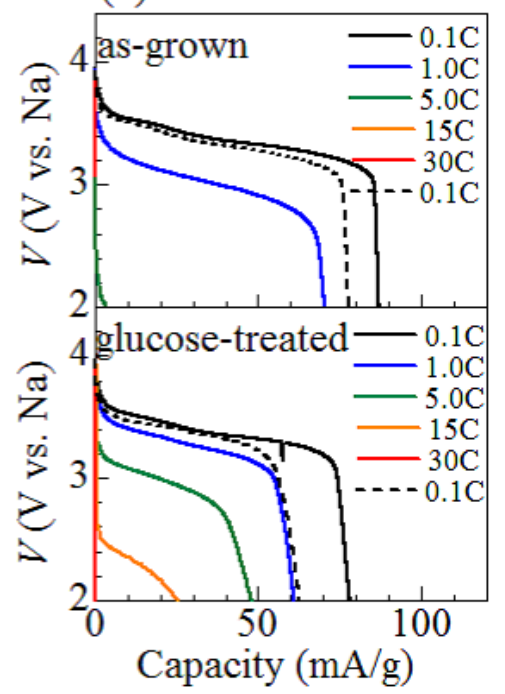

Figure 5. (a) Discharge curve at $0.1 \mathrm{C}$ of as-grown and glucose-treated Mn-PBAs. Red circles are voltage-derivative of capacity $(-\mathrm{d} q / \mathrm{d} V ; q$ and $V$ are capacity and voltage, respectively); (b) Discharge curves at various discharge rate of as-grown and glucose-treated Mn-PBAs. The lower and upper cut-off voltages were 2.0 and 4.2 V, respectively. The charge rate was fixed at $0.3 \mathrm{C}$.

In Figure 6, we plotted relative discharge capacity $\left(Q / Q_{1 \mathrm{st}}: Q_{1 \mathrm{st}}\right.$ is the value at the first cycle) against the cycle number. The charge rate was fixed at $0.3 \mathrm{C}$. In the as-grown Mn-PBA, the $Q / Q_{1 \text { st }}$ value rapidly decreases with cycle number. The cycle properties are significantly improved by glucose-treatment.

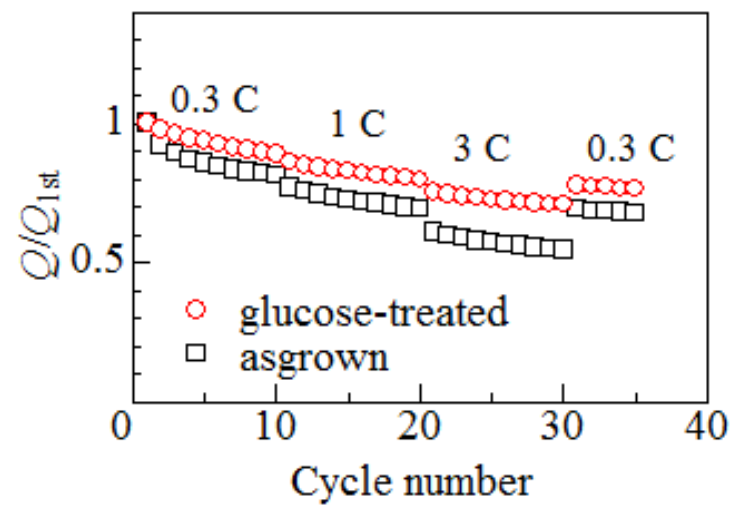

Figure 6. Cycle dependence of the discharge capacity $(Q)$ of as-grown and glucose-treated Mn-PBAs. $Q_{1 \text { st }}$ is the discharge capacity of the first cycle. The lower and upper cut-off voltages were 2.0 and $4.2 \mathrm{~V}$, respectively. The charge rate was fixed at $0.3 \mathrm{C}$.

\section{Conclusions}

The thermal decomposition of the glucose modifies the surface state of Mn-PBA, without affecting the bulk crystal structure. The glucose treatment significantly improves the rate property of Mn-PBA in 
SIB. The critical discharge rate increases from $1 \mathrm{C}$ (as-grown) to $15 \mathrm{C}$ (glucose-treated). Our observation suggests that the thermal treatment is quite effective, even for the insulating coordination polymers.

\section{Acknowledgments}

This work was supported by the Yasaki Memorial Foundation for Science and Technology and also by a Grant-in-Aid for Scientific Research (No. 21244052) from the Ministry of Education, Culture, Sports, Science and Technology (MEXT), Japan. The elementary analysis of Mn-PBA was performed at the Chemical Analysis Division, Research Facility Center for Science and Engineering, University of Tsukuba. We are grateful to Ms. Isaka and Dr. Takeguchi in NMCP for preparation and characterization of TEM samples.

\section{Author Contributions}

Y. M. planed the overall the experiment and performed the Rietveld structural analysis. K. G. synthesized and characterized the as-grown and glucose-treated Mn-PBAs. T. S. investigated the SEM images and cycle properties of the as-grown and glucose-treated Mn-PBAs.

\section{Conflicts of Interest}

There are no known conflicts of interest associated with this work.

\section{References}

1. Matsuda, T.; Kim, J.E.; Moritomo, Y. Universal thermal response of the Prussian blue lattice. Phys. Rev. B 2009, 79, doi:10.1103/PhysRevB.79.172302.

2. Imanishi, N.; Morikawa, T.; Kondo, J.; Takeda, Y.; Yamamoto, O.; Kinugasa, N.; Yamagishi, T. Lithium intercalation behavior into iron cyanide complex as positive electrode of lithium secondary battery. J. Power Sources 1999, 79, 215-219.

3. Imanishi, N.; Morikawa, T.; Kondo, J.; Yamane, R.; Takeda, Y.; Yamamoto, O.; Sakaebe, H.; Tabuchi, M. Lithium intercalation behavior of iron cyanometallates. J. Power Sources 1999, 81-82, 530-534.

4. Okubo, M.; Asakura, D.; Mizuno, Y.; Kim, J.D.; Mizokawa, T.; Kudo, T.; Honnma, I. Switching redox-active sites by valence tautomerism in Prussian blue analogues $A_{x} \mathrm{Mn}_{y}\left[\mathrm{Fe}(\mathrm{CN})_{6}\right] n \mathrm{H}_{2} \mathrm{O}$ (A: K, Rb): Robust frameworks for reversible Li storage. J. Phys. Chem. Lett. 2011, 1, 2063-2071.

5. Matsuda, T.; Moritomo, Y. Thin film electrode of Prussian blue analogue for Li-ion battery. Appl. Phys. Express 2011, 4, 047101.

6. Moritomo, Y.; Takachi, M.; Kurihara, Y.; Matsuda, T. Thin film electrodes of Prussian blue analogues with rapid $\mathrm{Li}^{+}$intercalation. Appl. Phys. Express 2012, 5, 041801.

7. Lu, Y.; Wang, L.; Cheng, J.; Goodenough, J.B. Prussian blue: A new framework of electrode materials for sodium batteries, Chem. Commun. 2012, 48, 6544-6546.

8. Matsuda, T.; Takachi, M.; Moritomo, Y. A sodium manganese ferrocyanide thin film for Na-ion batteries. Chem. Commun. 2013, 49, 2750-2752. 
9. Takachi, M.; Matsuda, T.; Moritomo, Y. Cobalt hexacyanoferrate as cathode material for $\mathrm{Na}^{+}$ secondary battery. Appl. Phys. Express 2013, 6, doi:10.7567/APEX.6.025802.

10. Yang, D.; Xu, J.; Liao, X.Z.; He, Y.S.; Liu, H.; Ma, Z.F. Structure optimization of Prussian blue analogue cathode materials for advanced sodium ion batteries. Chem. Commum. 2014, 50, 13377-13380.

11. Lee, H.W.; Wang, R.Y.; Oasta, M.; Lee, S.W.; Liu, N.; Chi, Y. Manganese hexacyanomanganate open framework as a high-capacity positive electrode material for sodium-ion batteries. Nat. Commun. 2014, 5, doi:10.1038/ncomms6280.

12. Wang, L.; Song, J.; Qiao, R.; Wray, L.A.; Hossain, M.A.; Chung, Y.D.; Yang, W.; Lu, Y.; Evans, D.; Lee, J.J.; et al. Rhombohedral Prussian white as cathode for rechargeable sodium-ion batteries. J. Am. Chem. Soc. 2015, 137, 2548-2554.

13. Yu, S.; Li, Y.; Lu, Y.; Xu, B.; Wang, Q.; Yan, M.; Jing, Y. A promising cathode material of sodium iron-nickel Hexacyanoferrate for sodium ion batteries. J. Power Sources 2015, 275, 45-49.

14. You, Y.; Wu, X.L.; Yin, Y.X.; Guo, Y.G. High-quality Prussian blue crystals as superior cathode materials for room-temperature sodium-ion batteries. Energy Environ. Sci. 2014, 7, 1643-1647.

15. Ravet, N.; Chouinard, Y.; Magnan, J.F.; Besner, S.; Gauthier, M.; Armand, M. Electroactivity of natural and synthetic triphylite. J. Power Sources 2001, 97-98, 503-507.

16. Huang, H.; Yin, S.C.; Nazar, L.F. Approaching theoretical capacity of $\mathrm{LiFePO}_{4}$ at room temperature at high rates. Electrochem. Solid State Lett. 2001, 4, A170-A172.

17. Chen, Z.; Dahn, J.R. Reducing carbon in $\mathrm{LiFePO}_{4} / \mathrm{C}$ composite electrodes to maximize specific energy, volumetric energy, and tap density. J. Electrochem. Soc. 2002, 149, A1184-A1189.

18. Chung, S.Y.; Bloking, J.T.; Chiang, Y.M. Electronically conductive phospho-olivines as lithium storage electrodes. Nat. Mat. 2002, 1, 123-128.

19. Franger, S.; Bourbon, C.; Gras, F.; Franger, S.; Bourbon, C.; Gras, F. Optimized lithium iron phosphate for high-rate electrochemical applications. J. Electrochem. Soc. 2004, 151, A1024-A1027.

20. Moritomo, Y.; Kurihara, Y.; Matsuda, T.; Kim, J.E. Structural Phase Diagram of Mn-Fe Cyanide against Cation Concentration. J. Phys. Soc. Jpn. 2011, 80, doi:10.1143/JPSJ.80.103601.

21. Moritomo, Y.; Matsuda, T.; Kurihara, Y.; Kim, J.E. Cubic-Rhombohedral Structural Phase Transition in $\mathrm{Na}_{1.32} \mathrm{Mn}\left[\mathrm{Fe}(\mathrm{CN})_{6}\right]_{0.83} 3.6 \mathrm{H}_{2} \mathrm{O}$. J. Phys. Soc. Jpn. 2011, 80, doi:10.1143/JPSJ. 80.074608.

22. Izumi, F.; Momma, K. Three-dimensional visualization in powder diffraction. Solid State Phenom. 2007, 130, 15-20.

(C) 2015 by the authors; licensee MDPI, Basel, Switzerland. This article is an open access article distributed under the terms and conditions of the Creative Commons Attribution license (http://creativecommons.org/licenses/by/4.0/). 